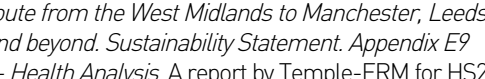
- Heath Analysis. A report by Temple-ERM for HS2
Ltd. London: Temple-ERM, 2013.

Department of Health. Preventing suicide in England
A cross-government outcomes strategy to save

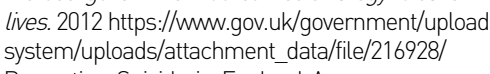
Preventing-Suicide-in-England-A-cross-government-
outcomes-strategy-to-save-lives.pdf faccessed 7 Jan HS2 Ltd. Key Dates. http://mmw.hss2.org. uk/about

DOl: 10.3399//jigp14X677004

\section{Will the age of austerity} save the NHS?

I have always been a passionate supporter of the NHS and initially viewed the Nicholson
challenge as a threat to the future of the challenge as a threat to the future of the
NHS; now though I wonder if it may actually NHS; now though I
save the NHS.

Among the many good things the last government did for the NHS there were changes that have significantly increased costs without improving quality of service. Agenda for change, the working time directive, consultant contracts and GP opt outs for out of hours all improved quality of life for staff, but have not improved health outcomes for improving outcomes has also reduced productivity Innovations in patient senvices, such as walk in centres, NHS Direct and Darzi centres, again driven more by wants than needs, have improved access without improvements in health outcomes. This has come at a time of previously unimaginable advances in quality of life and life expectancy, with the elderly population in some areas A rapidly increasing elderly population with falling productivity will make current NHS provision unaffordable within a generation. With the population growing and health cost inflation exceeding GDP growth even pre-2008 levels of funding will soon be insufficient without significant structural reform. While it is tempting to let our of affordability is coming and if we don't plan for this, we will soon reach a point where a publicly-funded, universal free healthcare system will be unaffordable. Prior to this, health and social care costs will gradually throttle our economy as demand increases. Depressing though this is, we have the opportunity to avert disaster. Humans have a embrace this to evolve our health delivery for the next few decades. In times of plenty changes in public services were often based on wants rather than needs. In the nex decade, Changes will have to be based on patient needs. As long as the patient is at the that improve productivity and improve care, can reshape the way we deliver care for ou population in the 21st century. Failure to embrace this change will result in a health system like the US, where only the rich have access to health care.

Rob J Daniels,

Townsend House Medical Centre, Seaton. E-mail: rob.danielsianhs.net

DOl: 10.3399//bjpp14X677022

\section{Reducing inappropriate}

\section{A\&E attendances}

Ismall et al clearly show that interventions in inappropriate attendances a cider emergency departments (A\&E), nor increase rent self-care 1 In Belgium 'Flanders) w observed a large increase in attendance of young children at primary care out-of-hours of a general practice cooperative (GPC). Recenty, data from new $\mathrm{PCOOH}$ services in colocation with A\&E showed nearly identica findings. Patients increasingly use the GPC, While palient huxes to he A\&E remain stable. bese observations can be party explained, not meant to improve overall efficiency of the healthcare system, but rather a response to increasing strain on $\mathrm{OOH}$ care: lowering numbers of GP equivalents, feminisation of workforce, and decreasing safety during home visits were principal drivers for these changes. From earlier work, we know tha patients tend to choose $\mathrm{PCOOH}$ services they like a proicus experiences and the co-payment does not significantly influence health seeking behaviour. ${ }^{5}$ Patients do no end to think in primary and secondary care when in (perceived) need for urgent care. To change patient behaviour, we need well-designed, multifaceted intervention envisaging high quality and sustainable health care, not in response to dissatisfied groups of and their payers collaborate to establish integrated models of care. In Belgium (Flanders) this would mean structural collaboration of A\&E and PCOOH services, and not competition for the majority of the GPs and medical specialints numbers A\&E, our professionals seem ready for this Financial issues of these senices need to be tackled as stakes are high for all stakeholders. Raising public awareness about appropriate health services use is of major importance as well. ${ }^{6}$ From the BBC Masterchef series we learn nearly every day that good cooking is possible for everyone. However, we did not with urgent needs within our health system.

Hilde Philips,

PhD, Primary and Interdisciplinary Care E-mail: hilde.philipsauantwerpen.be.

Barbara Michiels, Samuel Coenen, Roy Remmen,

Primary and Interdisciplinary Care Antwerp. Antwerp, Belgium.

REFERENCES nappropriate accident and emergenchy dep

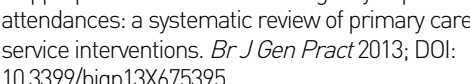

Philips $\mathrm{H}$, Remmen R, Van Royen P, etal. What's the
effect of the implementation of general practitioner cooperatives on caseload? ? Prospective intervention
study on primary and secondany care. BMC Health
Serv Res 2010; 10: 222. Streffer ML, van Bergen J. Philips H, etal
Rapoort Hulisartsenvachtost Antwerpen

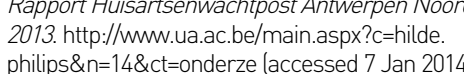

Philips H., Mahr D, Remmen R, etal Experience: the
most critical factor in choosing after-hours medical care. Qual Saf Health Care 2010; 1966): 3

E-mail: mohammed.hossainanhs.net

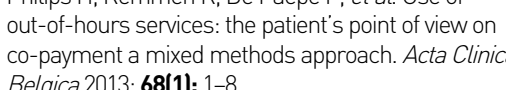
Belgica 2013; 681(1): 1-8.

- Philips $\mathrm{H}, \mathrm{Remmen} R$, De Paepe $\mathrm{P}$, etal . Out of
hours care: a profile analysis of patients attending the

emergency department and the geneneral practitioner
on call. BMC Fam Pract 2010; 11 : 8 .

DOl: 10.3399/bjpp14x67703

Studying and reducing DNAs to improve access system for appointments which we had for over 10 years but were not performing well on access because of a high number of hatents who did not attend (DNA. We often appointments were being wasted. I noticed that another local practice which permitted advance booking only 2 days ahead scored Another local practice was pilour practice. day booking system with no anpointments booked in advance, from June 2013

We calculated thatwe had nearlythe correct number of GP and nurse appointments per 1000 patients, per week. The Local Medical Committee had advised 100 appointments per 1000 patients per week. We are an average

the $80 \%$ of DNAs had booked 3 showed 7 days previously so we changed to 1 week advance booking system from 1 July 2013 with $50 \%$ of appointments bookable in advance and $50 \%$ avallable on the day, for GP appointments but not nurse appointments. The 'same day appointments were unblocked on the day at 8 am each morning to prevent them being booked online

A repeat audit of DNAs in October 2013 booked more than 3 days ahead so we have just changed to a similar 3-day booking system from Monday 9 December 2013. This has reduced our DNAs and reduced stress within the practice. Other practices in the UK may wish to consider hese ideas. I have concluded right one for our practice and will probably be optimal for most practices.

Mohammed N Hossain

Senior Partner, Stanhope Surgen,

DOl: 10.3399/bjgp 14X677059

Predictive validity of selection for entry into postgraduate training in general practice

The recent paper by Patterson et al reports the encouraging and considerable predictive and situational judgment test (SJT) selection tests for performance on the two MRCGP formal examination components. The MCQ and the SJT correlate with the Appled Knowledge Test (AKT) at 0.85 and

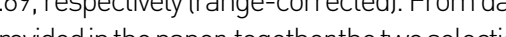
provits lests can be seen to predict 74-75\% of AKT with the old-style Clinical Skills Assessment CSA. 055,057, respectively range-corrected. together they predict $37-38 \%$ of CSA Scor variance. But the subsequent Selection Centre ISC), then a three station OSCE and correlating with the CSA at 0.41 (range corrected), is reported as only explaining an additional $2 \%$ SA score variance.

Given that a set of computer-delivered multichoice tests will cost $€ 100-200$ per candidat be at relatively very poor value, especially with about 5000 candidates being shortlisted for selection in $2012^{2}$ Perhaps the $f 5$ million-plus could be better used in supporting poorly-performing

Also, those of us who are responsible for devising OSCE assessments would be gratefu to learn how one with three stations, sing marked, can be devised such that its reliability Cronbactis al is 0.87 , when considerably reliability estimates; for example. MRCG CSA (13 stations) $0.77^{3}$ and iMRCS Part B (8 station subtests) $0.68-0.72$ and (10 statio subtests) $0.76-0.78$.

Richard Wakeford

Hughes Hall, University of Cambridge. Cambridge.

REFERENCES

政

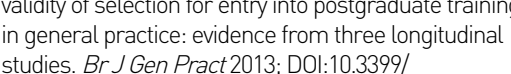

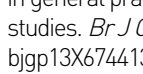
National Recruitment Office. Summary of the

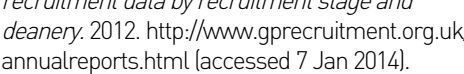
Statisticic 2011-12: Annual Report on the AKT and OSA and-exams/mrcgp-exam-overview/mrcgp-annu-

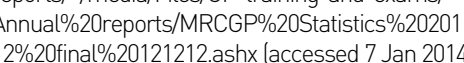
Intercollegiate Committee for Basic Surgical
Examinations $2012 / 13$ Annual Report htrp:I// Report_t 12_13 pdf laccessed 7 Jan 201/pd/Annua

\section{Why study?}

In November's Out of Hours, Trisha 'Whystudy?' " Her reflections were prompted by one of her self-funded, mature students completing his PhD while studying part-time and working as a full-time clinician.

She answered her own question by suggesting academic study resulted in both undertaking study for its own sake. As the student referred to in her article, perhans I can provide a perspective on the personal benefits of academic study

After approximately 25 years of nonacademic full-time clinical practice, I felt at a crossfoads. I wondered what I was going an be immensely fulfilting but it practice become mind-numbing under the can also to care for a seemingly unending stream of

Academic study provided an opportunity for me to pause, reflect on, and understand my experience within a larger context than my own practice. I found it mmensely satisfying provide about big ideas and academic stuad

produced many side benefits It inic study my self-confidence and self-esteem. My information searching and retrieval skills, improved. My ability to write coherently Without resortting to wild hyperbole continues
to develop. Even my spelling improved. Academic study changed both my way of thinking and approach to problems. I learned to evaluate how arguments are constructed, recognise rhetoric, and most importantly I learned to be sceptical and not to accept conclusions at face-value.

Academic study requires considerable Having the opportunity to observe full-time academics for the past decade made me main reason for prolonged ac. for $\mathrm{me}$, the main reason for prolonged academic study being I plan to continue my clinical practice and remain a hobbyist researcher. I now realise there are many opportunities to do meaningful research on a shoestring budget more budget at all. I look forward to many Don Eby

Emergency Department, Grey Bruce Healt E-mail. Oebros Sound, Granio, Canada. 
REFERENCE

631616): 595.

Dol: 10.3399/bigp 14X677013

GPs' job satisfaction: doctors who chose general practice early or late

In their study on GPs' job satisfaction Lambert after graduation. The authors conclude that the level of job satisfaction was generally high among both late and early choosers. Most GPs turn to general practice after initially preferring another speciality at the beginning
of their career and the majority will have a of their career and
satisfying career.

To understand the factors behind the choice, we questioned 198 students' in the Faculty of Toulouse (South-West France) about their reasons for choosing general practice. ${ }^{2}$ The result of our survey was that a GP career was chosen for its diversity and the doctor-patient relationship, with the fact that it is a speciality often held in low 744 had hesitated between general practice and another medical speciality, $66 \%$ 131) said that general practice was their first choice. Their positive choice in favour of general practice was based on several key factors: the characteristics of the profession, training in a general practice, the quality of education, he conditions of future practice the convinced, with a conscious preference for general practice; the visitors from the north of France, attracted by the southern climate and the characteristics of the profession; the opportunists, particularly interested in doctor-patient relationship; the sedentary students, who have always lived in Toulouse and gave priority to personal choice of town was more ims fortant than the choice of speciality and those who chase the faculty for its quality of its teaching and its reputation. may give the impression that most doctors had chosen general practice as a last resort. In reality, the choice for general practice depends on many factors and prow understand practitioners' level of job satisfaction. This is an important factor that not be overlooked.

Marie E Rouge Bugat University of Toulouse, France. E-mall: marieeve.rouge-bugatidumgMichel Bismuth, Stephane Oustric, University of Toulouse, France.

REFERENCES doctors who chose general practice early or altate. Br Gen Pract 2013; Dol: 10.339//bigp 13X6/4404. . Bismuth M, Rouge-Bugat ME, Poutrain JC, et al
Medecine 2013:9: $136-141$

Dol: 10.3399/bjpp14X677040

\section{Are GP career}

intentions more

prevalent in UCL

Primary Health Care

iBSc students?

Peile mentions the importance of the role of medical schools in influencing students to consider a career in gener determinants on medical students' career choices and specifically choosing a career in general practice $e^{2.3}$ is important because medical schools can now tailor their teaching to overcome the problem of the declining number of GPs. Little research has been done on the career impact of $\mathrm{BSC}$ degrees, and less on BBScs in primary health care have often influenced students academically and discouraged them from becoming GPs ${ }_{45}$ The PHC iBSC course is a relatively new course at UCL, and it aims to widen the scope of medical education by developing research, clinical and critical appraisal skills as well as exploring general practice in depth We carried out a case-control study online survey. This study was approved by the UCL ethics committee. All PHC graduates from the 2009-2010 to the 2012-2013 cohor were identified. Each was matched lin terms of iBSc completion) with three students from any other IBSC degrees from UCL. Questionnaires online were then made response ratem 33 out of 104 $(31.73 \%$. 13 (of 15) PHC students expressed a degree of interest in general practice, while only 8 lof This was statistically significant $\mathrm{OOR}=8.125$ $P=0.002$ ). There were no other correlations between GP intention and sex, stage of medical school or ethnicity. This study
suggests that the PHC iBSc is associated with a stronger interest in a GP career, and demographic variables in this group did not impact on GP career intention. A potential bias is that the students enrolled on the PHC course may already have developed a strong interest in a GP career prior to their IBSC year which may have influenced our results.
APHC BBSc course betterinforms about general practice, although being better informed alone does not directly translate to a stronger GP career intentio

Ryo Fukaura,

Medical Student, University College London E-mail: ryo.fukaura. 1010ucl.ac.uk

Melvyn Jones,

University College London

REFERENCES

judgements. Br J Gen Pract 2013; ; 3361616 : :565-566

. Ali B, Jones M. Do medical students want to become
GPs? Br J Gen Pract 2003; $53(488)$ : 41 .

Henderson E. Berlin A Fuller J. Atitiude of medical
students towards general practice and gemeris

students towards general practice and general
practitioners. Br J J en Pract 2002; 521478): 359-363

McManus IC, Richards P., Winder BC. Intercalated

degrees, learning styles, and career preferences:
prospective longitudinal study of UK medical students

Jones M, Hutt P, Eastwood S, Singh S. A Best
evidence systentic review of the impact of an

intercadaded BSc on medical student pertormance

Professional Education 2013. http://www.

bemecollaboration.org/Published+Reviews/BS

Jones M, Lloyd M, Meakin R.An in itercalated BSc in

primary heath care: an outtine of a new course. Med

DOl: 10.3399/bjgp 14X677077

\section{Text messaging to}

\section{promote health}

Douglas and Free's qualitative study'

show that text mosmised controlled trial

show that text messaging offers a valuable way of supporting people trying to give up wider potential in health promotion, including In September 2013 we carried out a patient and public involvement user group to investigate what female genitourinary medicine encouraging regular STl checks, use of long HIV testing. These three topics were chosen in response to the 2013 Framework for Sexual Health Improvement, which highlights sexually transmitted infections (STIs), teenage pregnancies and late diagnosis of HIV as major public health problems. Consecutive women aged 16-24 years attending the Courtyard Sexual Health Clinic invited to complete a confidential anonymous questionnaire and to express opinions. The response rate was $100 \%(30 / 30)$, and the mean age of participants was 20 years Irange 16-24 years.

Text 1: 'Time for your check-up? Please telephone ...' 27/30 $(90 \%)$ thought this reminder a good idea, and 2330

Text 2: Have you thought about tging a contraceptive implant or coil so you don't have to keep remembering? Ask when you go for your check-up. 23/30 (77\%) were happy to receive this, and 20/30 (67\%) would ask about LARC.

Text 3: 'Have you thought about HIV testing . Ask when you have your check-up. $25 / 30$ would ask about HIV testing at their next check-up

Comments included: 'A really good idea and could help a lot of women. Very straight and to the point. "Young girls don't think about this so it's good to give them awareness. Overall there was a positive response to reciving all three texk, and over two-thirds We agree with Douglas and Free' that it is important for healthcare professionals to understand patient experiences of a text messaging service. User groups can also be helpful. Text messages are increasingly used for appointment reminders in primary pre and could have potential as

Clare Michell

Academic ST4 GP, Population Healt

Sciences and Education, St George

University, London.

E-mail: cmichelllasgul.ac.uk

Pippa Oakeshot

Reader in General Practice, Population
Health Sciences and Education, St George's University, London.

REFERENCES corner': experiences of smoking-cessation support
via text message. Br J Gen Pract 2013; DOI: 10.3399/
bigp 136674559 2. Free C, Knight R, Robertson S, etal. Smoking
cessation support delivered via mobile phone tex

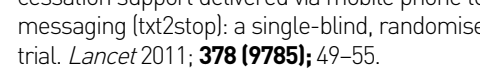

3. Department of Health 2013. A Framework for Sexual
Health Improvement in England. https://wnw.gov. uk/government/publications/a-framework-for-

sexual-health
Jan 2014).

DOI: 10.3399//bigp14X677086

Social media in general practice: a ray of hope

or a can of worms?

We read with interest the letter by Lad and McGowan' in which they presen their views on the future of patient-doctor to their suggestions, there are four poin we would like to address. Firstly, while paperless NHS is a desirable, and perhap distinction between IT and draw a critica achieving the "'Surgery'. Indeed, the lack of security in social media is well documented and has many ethical and legal implications for patient confidentiality and consent two inalienable aspects of good medica practice.

Moreover, we disagree that the next logic step for IT in medicine is social media: there is communication Iletters and tele hat modes between GPs and patients are ineffective or disliked by patients. As the old mantra states: If it isn't broken, why fix it?' Effecting widesweeping change in the current climate financial strain would be challenging enoug without considering the steep learning curve Thi and praclice staff.

Thiralin white mobile text and email reportedly had positive outcomes, can we translate this to social media?5-6 Clearly, the former have significantly wider use across all demographics than social media. Furthermore, a move towards social media potentially increases the risk of excluding vast subsets of society who do not use or
not have access to such websites.
Finally, though the traditional paternalistic consultation is increasingly a thing of the past, in promoting telemedicine, there may be a danger of faling to adequately address patient concerns and overlooking key body language cues which would otherwise be apparent in face-to-face communication. in heapthion of wide-ranging social media device failure and website maintenance, which occur commonly, leading to frequent periods of impaired communication between doctors and patients

We commend Lad and McGowan in seeking improved patient-doctor communication, and agree that this should be a key area of future innovation and discourse among healthcare professionals. Overall, however, the practical and ethical detriments of social media in the healthcare setting outweigh letter. We feet, instead, hat the cur ent focus in healthcare IT development should remain for the moment with greater harmonisation of disparate patient information networks coupled with continuing development of electronic patient notes and records.

Mohammed U Halim,

Oriel College, University of Oxford, Oriel Square, OX1 4EW. E-mail: usmaan.halim(aoriel.ox.ac.uk

Akif Malik, Mohammad A Ali Medical Sciences Division University of Oxford, Oxford.

REFERENCES Pract 2013; 63161616: 574 -Zeev D, Neville RE. Ethical postings on Facebook J Journal of of cual Da Diagnosis Bourke J. Wessely S. Confidentiality. BMJ 2008; 336,

Etheics 2003 . Some linits of informed consent. J J 4 ed

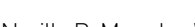
consultationsden W. McCowan C, et tal. Email 2004; 12(4): 207-214

Neville RG, Reed C, Boswell B, etal. Early

experience of the use of short message service
ISMS technology in routine clinical care. Inform
Prim Care 2008: 1631 203-211

DOl: 10.3399/bigp 14X677095 